\title{
Teaching EEG 6 : A neonate with suspected subtle seizures
}

\section{Sarma G.R.K. ${ }^{1}$, So N² , Elizabeth VT ${ }^{3}$}

${ }^{1}$ Professor of Neurology, St. Johns' Medical College Hospital, Bengaluru, India

${ }^{2}$ Clinical Professor, Department of Neurology, University of Washington Medical Center, USA

${ }^{3}$ EEG technologist, St. Johns' Medical College Hospital, Bengaluru, India

A 21 day old term-baby underwent EEG for evaluation of possible subtle seizures. Her EEG tracings are shown below (figures 1 \& 2 ).

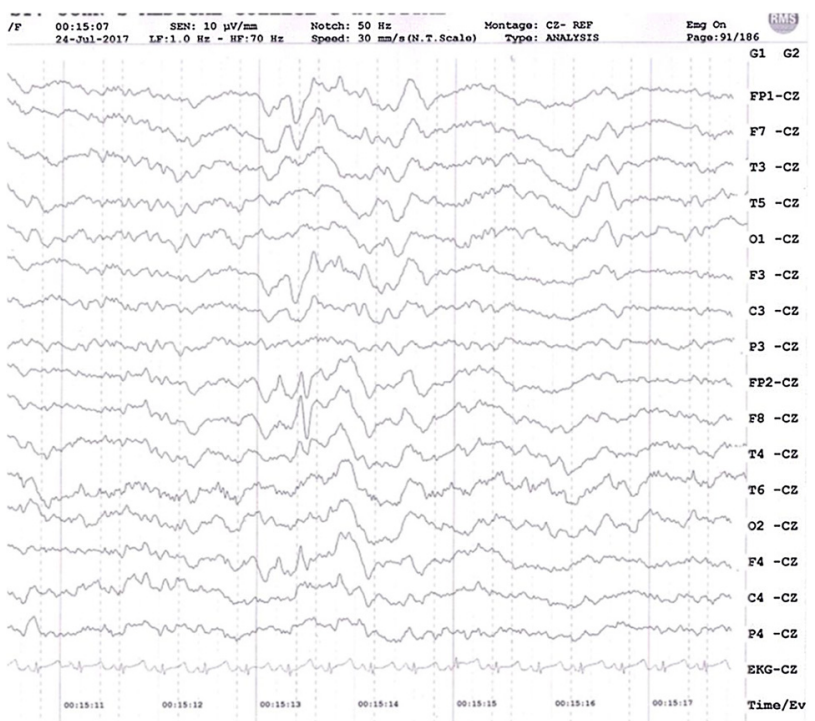

Figure 1

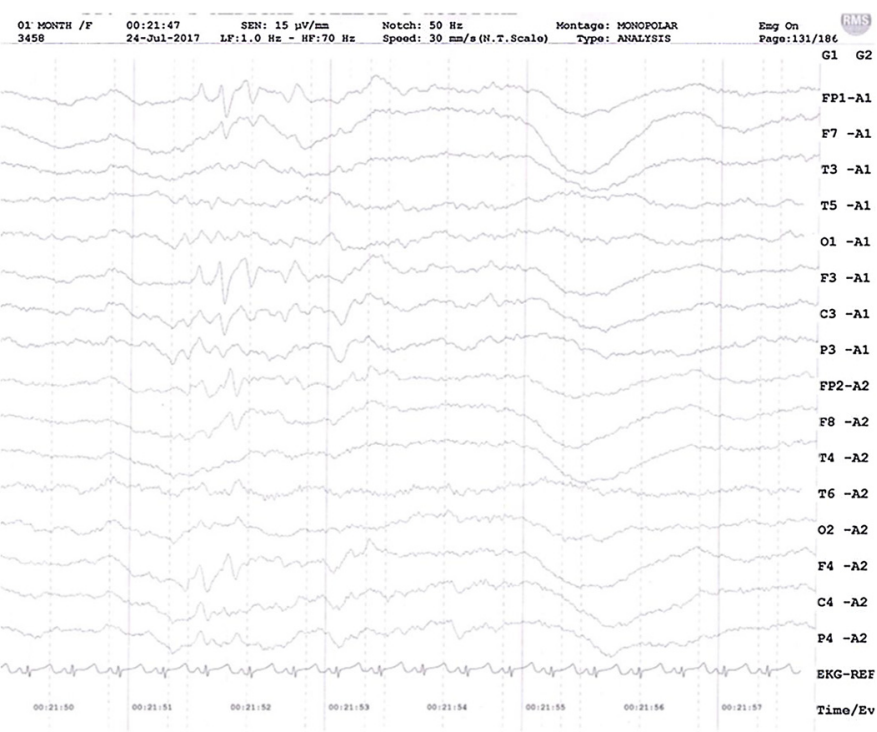

Figure 2

\section{Questions:}

1. Describe the paroxysmal activity seen in the two tracings.

2. Which physiological waveforms in neonates appear in frontal regions?

3. Are these paroxysmal discharges in this neonate physiological or pathological?

\section{Answers:}

1. There are sharp waves with biphasic morphology occurring asynchronously in right and left frontal regions. There is an initial negative component followed by a positive component in these discharges.

2. Biphasic frontal sharp transients occurring in normal neonates are called Encoches Frontales. They are described as symmetric and synchronous frontal biphasic sharp waves that appear at 35 weeks gestation and disappear by 8 weeks postpartum ${ }^{1,2}$. Their initial component is surface negative $(50-150 \mu \mathrm{V}, 200 \mathrm{~ms}$ duration $)$ and is followed by surface positive slower wave. They are seen in quiet sleep or active sleep and less often in awake or transitional states.

However, more recently, Crippa et al showed that Encoches Frontales can also be asynchronous or even unilateral in normal neonates ${ }^{3}$. They emphasize that only the density of these sharp waves, not their asymmetry or asynchrony, provides a clue to underlying disease state.

3. In the above EEG tracings, the frontal sharp waves are biphasic with initial surface negative wave followed by surface positive slower wave, similar to the morphology of encoches frontales. They are not synchronous in this EEG, but this asynchronicity was not considered abnormal. 


\section{Learning point:}

Bilateral symmetrical, synchronous frontal sharp waves with biphasic morphology are considered physiological in neonates and are called Encoches Frontales.

An asymmetry or asynchrony of these discharges is not necessarily abnormal. Only an increased density of these sharp waves may be considered abnormal.

\section{References}

1. Arfel G, Leonardon N, Moussalli F. Density and dynamic of frontal sharp waves (encoches pointues frontales) during sleep in new-borns and infants. Rev Electroencephalogr Neurophysiol Clin. 1977 Jul-Sep; 7 (3):351-60.

2. Aatif M Husain. Review of neonatal EEG. Am J End Technol. 2005 (45): 12-35.

3. Crippa AC, Silvado CE, de Paola L, Scola RH, Fernandes RM, César Werneck L. Analysis of frontal sharp transients in 32 neonatal polysomnography in healthy fullterm newborns. Arq Neuropsiquiatr 2007; 65(2-A):222-227 